\title{
Fabrication and Optoelectronic properties of Fluoride tin oxides/porous silicon/p-Silicon heterojunction
}

\author{
Hasan A. Hadi \\ Department of Physics, College of Education, University of Al-Mustansiriyah, Baghdad, Iraq \\ E-mail address: ha_yaba@yahoo.com
}

\begin{abstract}
In this paper, formation of a nanostructure semi transparence fluoride tin oxides (FTO) by spray pyrolysis technique on porous silicon PS layer. Porous silicon PS layer was prepared by anodization of p-type silicon wafers to fabricate of the UV- Visible Fluoride-doped tin oxide /Porous silicon /p-Si heterojunction photodetector. Optical properties of FTO thin films were measured. The optical band gap of $3.77 \mathrm{eV}$ for $\mathrm{SnO}_{2}$ : Ffilm was deduced. From (I-V) and (C-V) measurements, the barrier height $\emptyset_{B}$ for FTO/PS diode was of $0.77 \mathrm{eV}$, and the built in voltage $\mathrm{V}_{\mathrm{bi}}$, which was of $0.95 \mathrm{~V}$. External quantum efficiency was $55 \%$ at $500 \mathrm{~nm}$ which corresponding to peak responsivity of $1.15 \mathrm{~A} / \mathrm{W}$ at $1 \mathrm{~V}$ bias. The PS band gap in the vicinity of PS/c-Si heterojunction was $1.38 \mathrm{eV}$.
\end{abstract}

Keywords: porous silicon; electrochemical etching; spray pyrolysis; fluoride-doped tin oxide film; nanostructures; SEM; AFM; photodetector

\section{INTRODUCTION}

Porous silicon has attracted much attention among technologists for developing optical and electronic devices [1]. In most literatures; the PS layer was considered to behave like a wide band gap semiconductor and assumed a Schottky barrier formed between the metal and the PS. In some cases, these metal contacts are replaced by transparent conductive oxide (TCO), such as tin oxide or zinc oxide, modified with dopants such as fluoride or aluminum, respectively. In these cases, knowledge about the contact properties is very scarce [2-4]. Among the various deposition techniques, spray pyrolysis is well suited for the preparation of doped tin oxide thin films because of its simple and inexpensive experimental arrangement, ease of adding various doping materials, reproducibility, high growth rate and mass production capability for uniform large area coatings [5]. Fluoride tin oxide has numerous applications because of their high optical transparency in the visible region, good electrical conductivity and the high infrared reflectivity [6-8]. The heterojunction interface offers many more controllable parameters which enable the designers to tailor the heterojunction device characteristics and fit the desired functions Heterojunction devices are playing an increasingly important role in optoelectronics [9]. In the present work, the properties of FTO films prepared by spray pyrolysis have been measured and morphology of porous silicon layer prepared by electrochemical etching was investigated by SEM and optical microscopy 
images. We investigated electrical and optoelectronic properties of $\mathrm{Al} / \mathrm{FTO} / \mathrm{PS} / \mathrm{p}-\mathrm{Si} / \mathrm{Al}$ heterojunction photodetector and analyzed.

\section{EXPERIMENTAL}

The schematic diagram of experimental setup used in the present work has been shows in Fig. 1. The single cell back-side contact was used to papered porous layer. In this cell, the Si wafer is placed on a copper disk and sealed through an O-ring, so that only the front side of the sample is exposed to the electrolyte. The copper disk has to be cleaned with a lapping machine in order to remove the oxide film that forms itself after many etching processes. The PS layer was fabricated by anodic etching of a silicon wafer p-type substrate, orientation (100) and a resistivity of 10-20 $\Omega \mathrm{cm}$ corresponding $1.34 \times 10^{15}-6.67 \times 10^{14} \mathrm{~cm}^{-3}$, etching cell using a mixture of aqueous hydrogen fluoride(purity $40 \%$ ) and methanol (purity $99 \%$ ), 1:1 by volume. The silicon was used as an anode while the cathode was of gold mesh to papered porous layer by photo electrochemical etching (ECE) technique. The silicon surface was etched with a current density of $5 \mathrm{~mA} / \mathrm{cm}^{2}$ for $3 \mathrm{~min}$ to form a PS layer about 117 $\mathrm{nm}$ thick and porosity of $65 \%$ in the dark and at room temperature. The estimate of the porosity and thickness of the PS layers was made by gravimetric measurement.

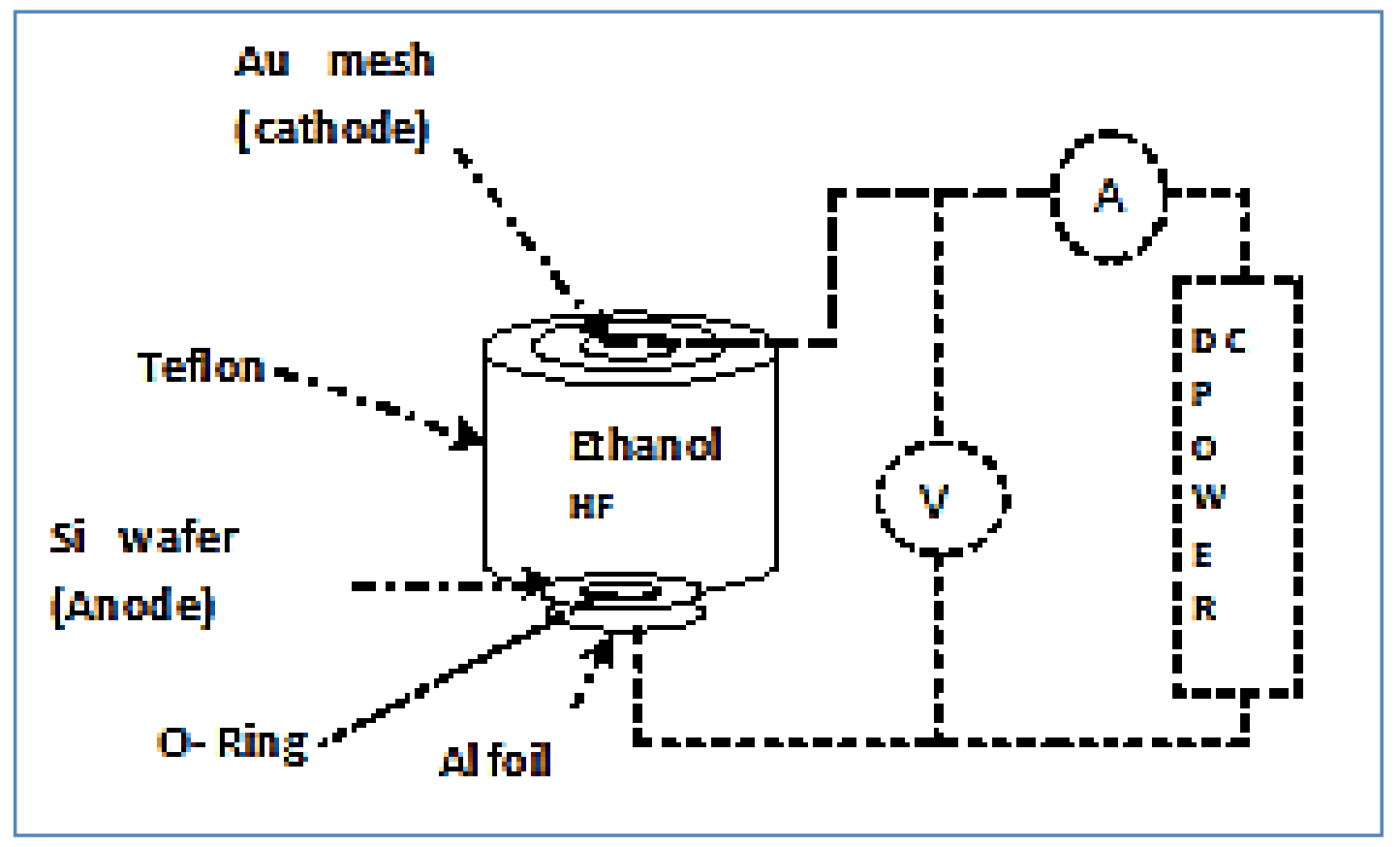

Figure 1. Schematic of the single cell back-side designed porous silicon fabrication system.

The chemical spray pyrolys is a versatile as well as a low-cost technique that has been used to deposit semiconductor films. In this process, a thin film is deposited by spraying a solution on a hot surface. The constituents react to form a chemical compound.

Thin layers $(103.3 \mathrm{~nm})$ of fluoride doped tin oxide (FTO) have been prepared on Microscopic glass slides $\left(2.5 \times 2.5 \mathrm{~cm}^{2}\right)$ and porous silicon $\left(1.5 \times 1.5 \mathrm{~cm}^{2}\right)$ based on p-type $\mathrm{Si}(100)$ substrates by using spray pyrolysis method. An aqueous solution of high purity tin 
chloride $\left(\mathrm{SnCl}_{4} \cdot 5 \mathrm{H}_{2} \mathrm{O}\right)$ with concentration of $0.1 \mathrm{M}$ was used as starting solution. A small amount (few drops) of concentrated hydrochloric acid $(\mathrm{HCl})$ was added to prevent hydrolysis. For fluoride doping, ammonium fluoride $\left(\mathrm{NH}_{4} \mathrm{~F}\right)(99 \%$ purity, BHD) dissolved in de-ionized water was added to the starting solution. The doping concentrations was varied of $15 \mathrm{wt} . \%$.

The carrier gas flow rate was maintained at pressure of $1 \times 105 \mathrm{~N} . \mathrm{m}^{-2}$. In both cases the preparation conditions were: the distance between the spray nozzle and the substrates $30 \mathrm{~cm}$. The spray time was $10 \mathrm{~s}$ and the spray interval at $\sim 3 \mathrm{~min}$. Totally time to spry a volume of solution was used to produce films and sprayed for $240 \mathrm{sec}$. The glass substrates temperature was maintained at $\left(405 \pm 2{ }^{\circ} \mathrm{C}\right)$ during the whole spraying process. The thickness of the film was determined by weighting method and it found to be. The FTO film and porous silicon layer were characterized by atomic force microscopy AFM, optical microscopy and scanning electron microscopy (SEM).

The I-V characteristics were analyses to examine the junction properties by using the following device configuration: Al/FTO/PS/p-Si/Al as shown in Fig. 2. measurements are performed using a stabilized d.c. power supply, type LONG WEI DC PS-305D 30 ranges (-1 to +1$) \mathrm{V}$. The current passing through the device is measured using a UNI-T UT61E Digital Multimeters. The capacitance-voltage $\mathrm{C}(\mathrm{V})$ measurements are performed at various frequencies by the use of hp4275A-MuTi-frequaency LCR meter -HEWLETT Packard. The $\mathrm{C}-\mathrm{V}$ characteristic of the diode was also evaluated in the voltage range from -1 to $1 \mathrm{~V}$ at the frequency $2 \mathrm{MHz}$.

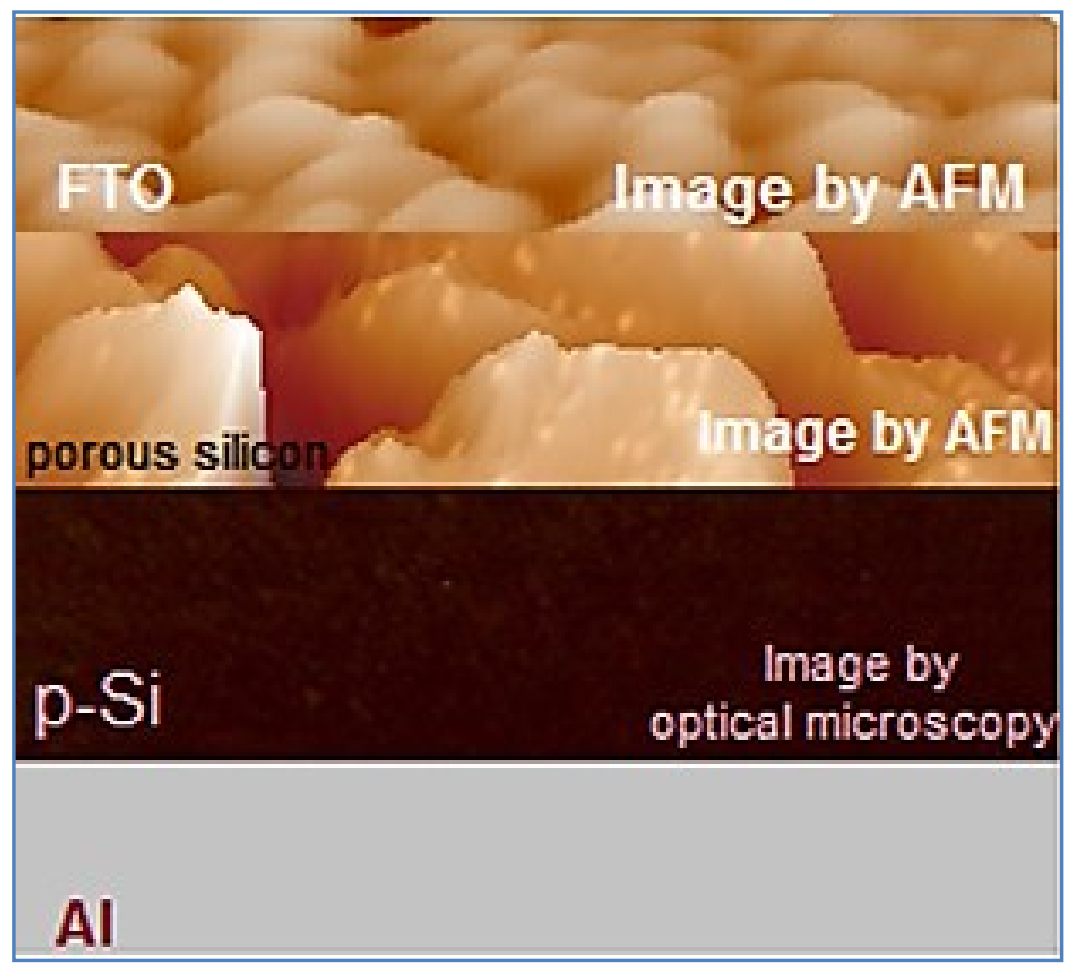

Figure 2. A schematic diagram of the FTO/PS/p-Si/A1/ heterojunction.

Measurements of photocurrent of heterojunction were done under white light of different illumination power densities supplied by a halogen lamp with power of $150 \mathrm{~W}$, which was connected to a Variac and calibrated by power meter. Optical transmittance was 
obtained by UV-1650PC SHIMADAZU UV-Visible spectrophotometer in the 300-1000 nm range, as for lower than $400 \mathrm{~nm}$ a strong absorption appears due to the glass substrate. The spectral responsivity of the $\mathrm{FTO} / \mathrm{PS} / \mathrm{p}$-Si heterojunction was measured by using a monochromatic with spectral range $(400-1200) \mathrm{nm}$. This measurement is done under reverse bias $1 \mathrm{~V}$. Figure 2 shows the structure of the $\mathrm{FTO} / \mathrm{PS} / \mathrm{p}-\mathrm{Si} / \mathrm{Al}$ configuration fabricated by planar front Schottky and backside ohmic contacts respectively.

\section{RESULTS AND DISSCUSION}

\section{1. Morphology of porous silicon layer and FTO film}

SEM and Optical images of the porous silicon are shown in Figure $3 a$ and $b$, respectively. The SEM image Fig. 3a reveals that etching effect of the large pore exposing a small portion of the surface layer. SEM images present different gray color degree inhomogeneous depending on the porosity of the layer, also optical microscopy image at $5 \mathrm{~mA} / \mathrm{cm}^{2}$ etching current density changes the flat surface of $\mathrm{p}-\mathrm{Si}$ to relatively rough surface but the porous layer has a small thickness and inhomogeneous structure as shown in Fig. 3b, and photograph image inset of Fig. $3 b$.

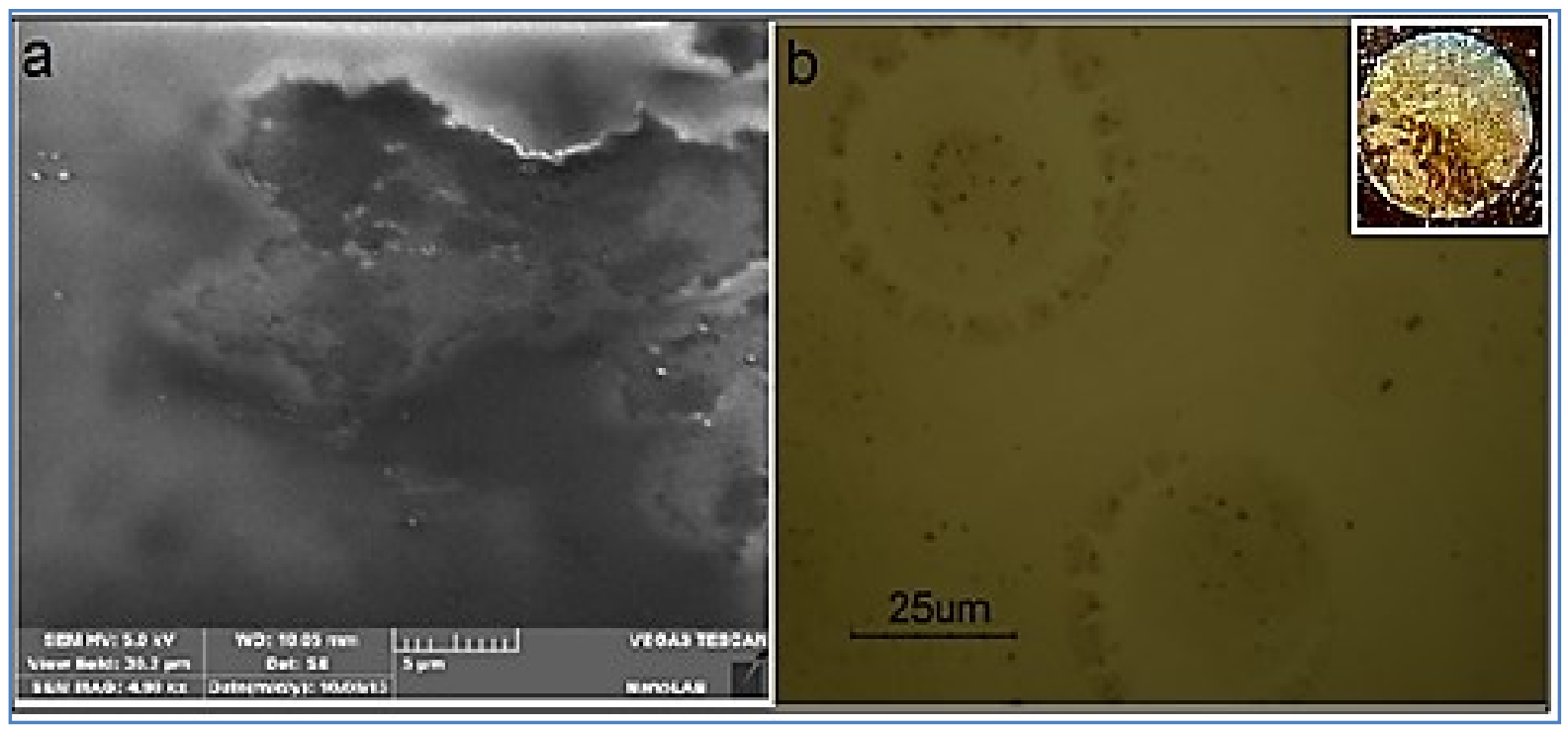

Figure 3. (a) SEM image of porous silicon and (b) Optical image of porous silicon on p-Si.

AFM was used to observe fresh FTO surface and profile morphology and from two dimensional image amplitude parameters, the root mean square ,ten point height, roughness average and the average diameter were $2.07,8.71,1.63 \mathrm{~nm}$ and $100.74 \mathrm{~nm}$ respectively. Atomic force microscopy (AFM) reveals three dimensional ordered arrays of spherical cavities and ellipse shape, which are organized in inhomogeneous domain with different orientations. 


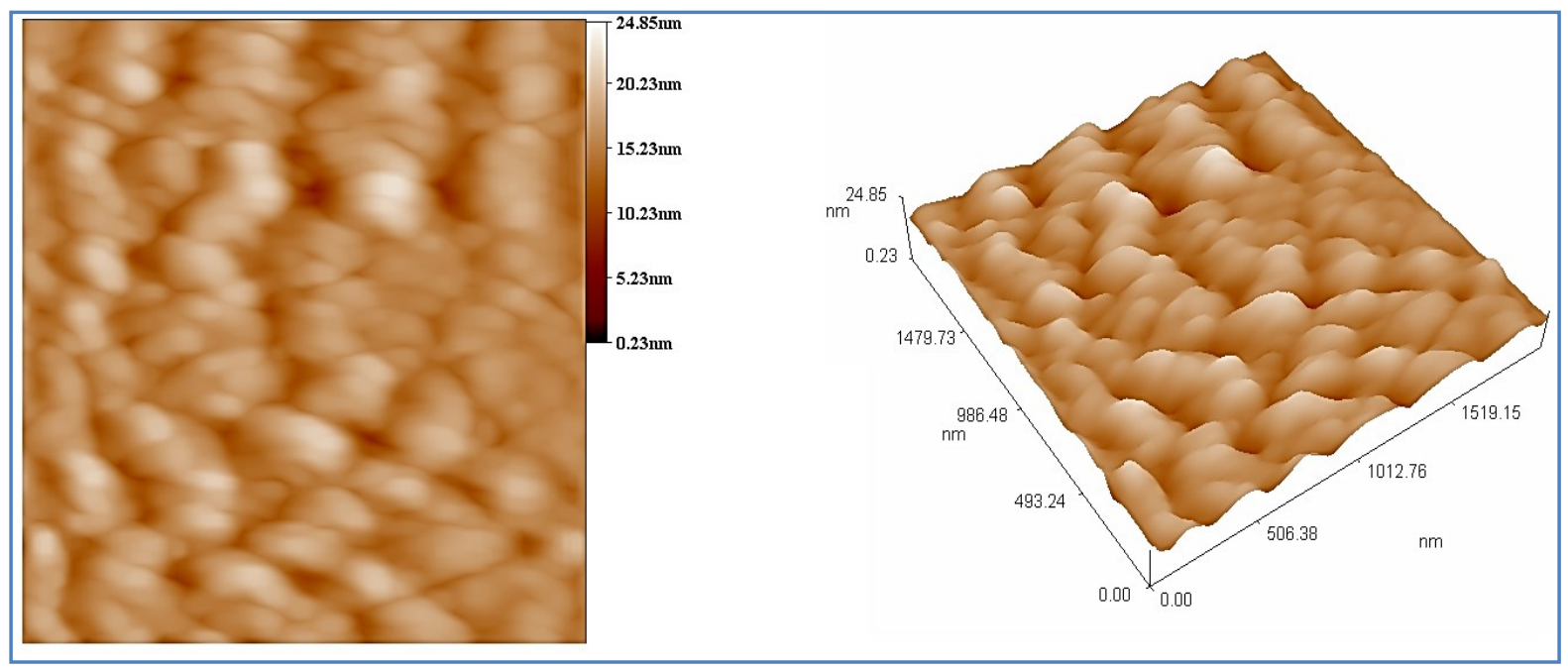

Figure 4. AFM images of 2D and 3D FTO on a surface of PS.

\section{2. Optical properties}

The inset in Fig. 5 shows a result of optical transmittance spectrum of the FTO film as function of wavelength. Spectrophotometric measurements on FTO layers which were grown on glass showed an average transparency about $70-77 \%$ in the visible and near infrared region as shown in Fig. 5.

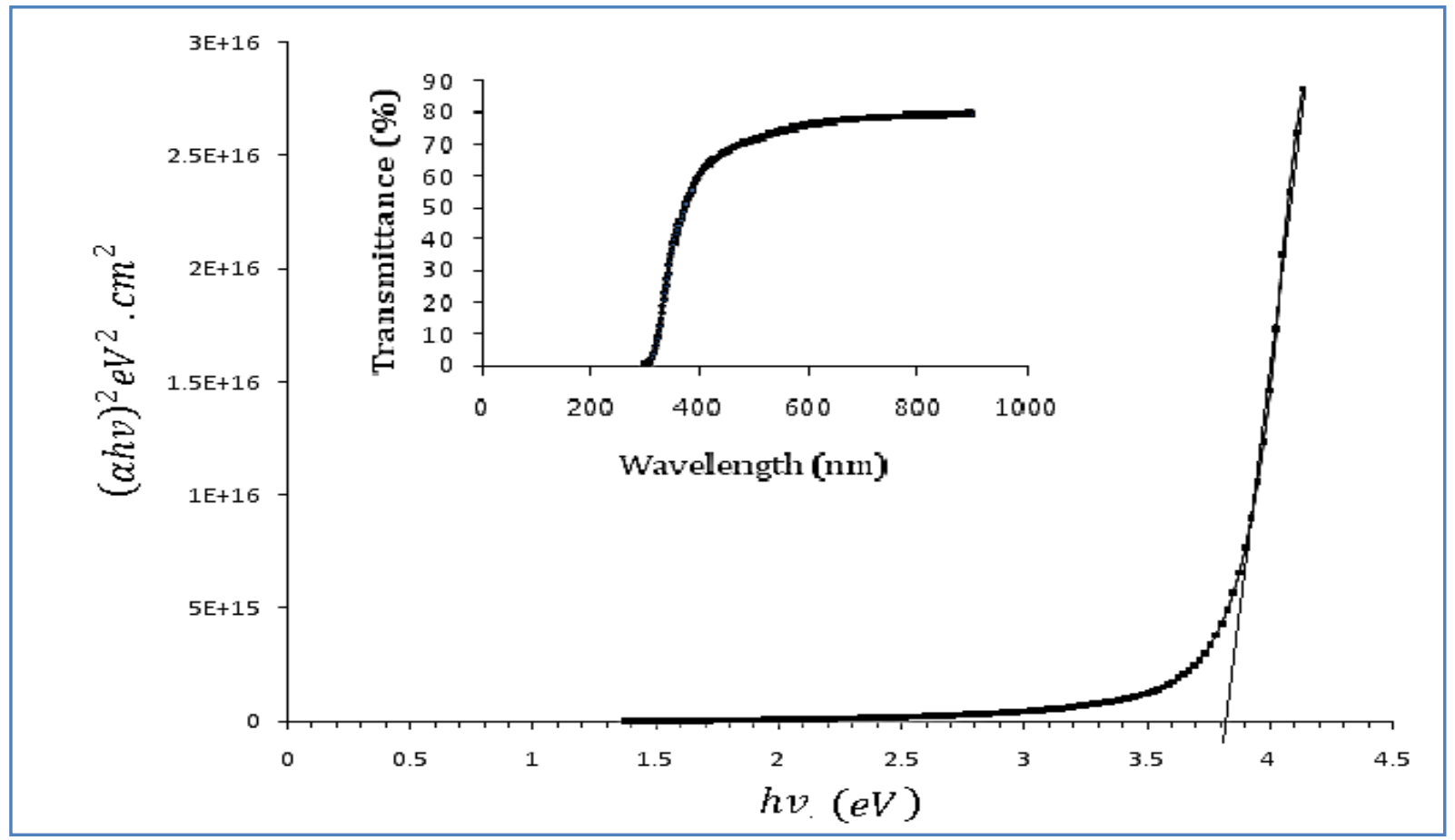

Figure 5. $(\boldsymbol{\alpha h v})^{2}$ versus $\boldsymbol{h} \boldsymbol{v}$ plot and left inset of Fig. transmittance spectrum of FTO film deposited on a glass substrate.

$\mathrm{SnO}_{2}: \mathrm{F}$ is a direct band gap semiconductor; the band gap is estimated from the plots of $(\alpha h v)^{2}$ versus hv and shown in Fig.5. From the diagram, the optical hand gap of $3.77 \mathrm{eV}$ for 
$\mathrm{SnO}_{2}: \mathrm{F}$ film is deduced, which represents a UV-visible region. This value is lower than to the value of published results [5]. This decrease in band gap can be attributed to a decrease in carrier concentration of the film due F doping. Similar optical band gap value was reported for the $\mathrm{SnO}_{2}: \mathrm{F}$ film [5]. One can notice that this value is very close to the band gap of promising materials for solar cells and optoelectronic devices.

\section{3. Electrical properties}

The dark I - V relationship of FTO/PS/p-Si heterojunction junction diode can be expressed as [10]:

$$
I=I \circ\left[\exp \left(\frac{q V}{n K T}\right)-1\right]
$$

where $I_{\circ}$ is the saturation current, $\mathrm{V}$ is the applied voltage, and $\mathrm{n}$ is the ideality factor. The $\mathrm{I}-\mathrm{V}$ characteristics are rectifying, as shown in Fig.6 and the rectification ratio at $\pm 1 \mathrm{~V}$ is approximately 84 . Within the applied voltages used in measurements, no breakdown was observed under reverse biasing. The rectifying behavior is attributed of FTO/PS Schottky barrier. The $n$ value of heterojunction can be determined from the slope of the straight line region of the forward bias log $\mathrm{I}-\mathrm{V}$ characteristics by expression from Eq. (1). It was found to be around 2.2, and this high value suggests that the due to trap-assisted recombination or to the presence of the thin native interfacial oxide layer and series resistance, and that agree with [11-12]. In this work, the barrier height $\emptyset_{B}$ for FTO/PS diode was of $0.77 \mathrm{eV}$, and the series resistance $R_{S}$ was about $10 \mathrm{k} \Omega$.

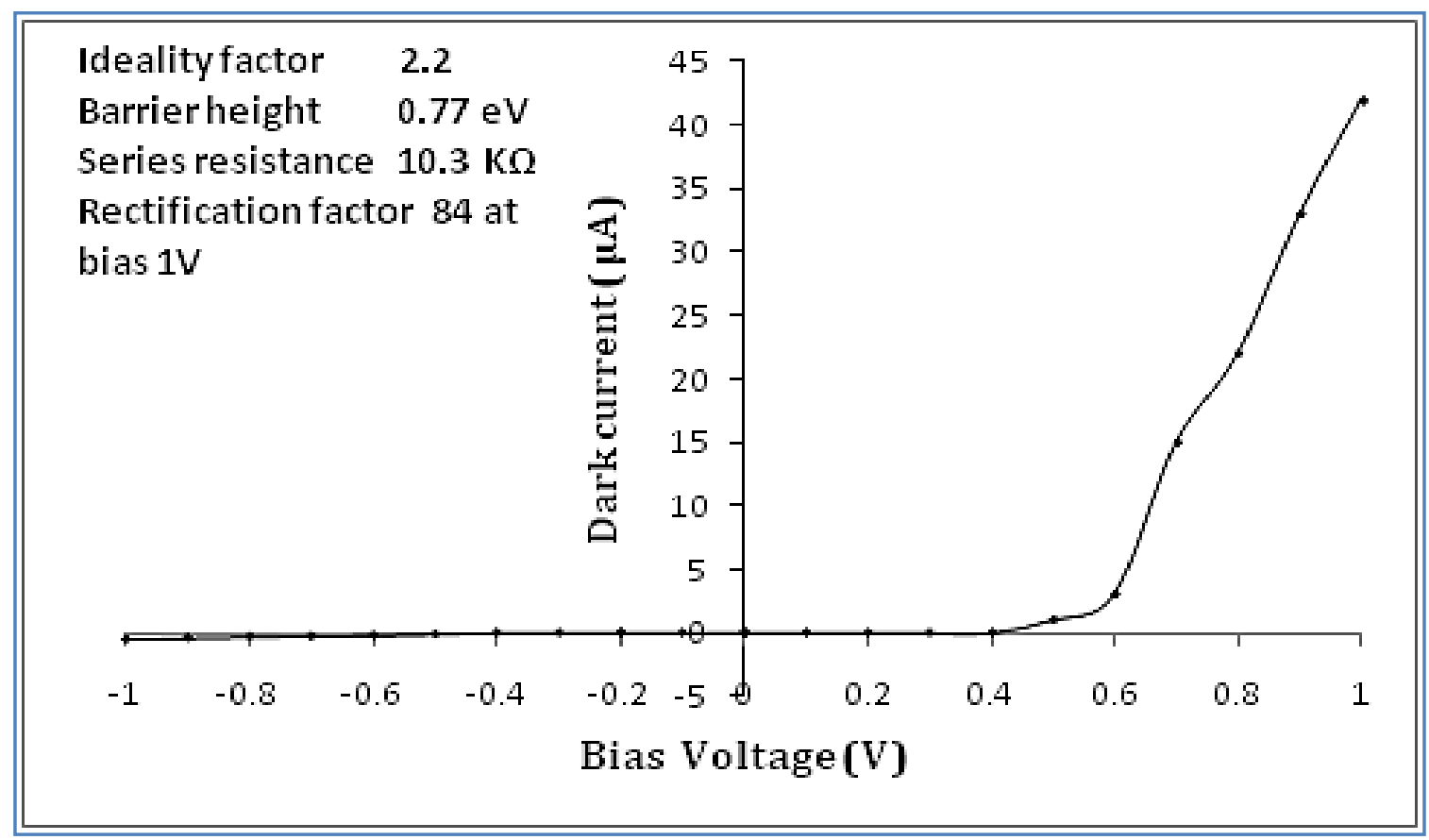

Figure 6. Dark current-voltage characteristics of FTO/PS/p-Si/Al structures. 
The band gap of FTO is larger than the energy of visible photons, and therefore, it is transparent to visible light. Visible light passes through the FTO film and the illumination light is strongly absorbed by the PS layer. Photocurrent observed under reverse bias conditions. It was found from the dark and photocurrent - voltage measurements of the fabricated $\mathrm{FTO} / \mathrm{PS} / \mathrm{p}$-Si/Al sandwiched heterojunction photodetector that the reverse dark current was about $0.5 \mu \mathrm{A}$ at $1 \mathrm{~V}$ bias where as the photoconductive current were $(113.2,138,170.5-184.2) \mathrm{mA} / \mathrm{cm}^{2}$ at $(12.75,28.6,109-206) \mathrm{mW} / \mathrm{cm}^{2}$ respectively. When the structure was illuminated, the electron-hole pairs generated in the depletion layer of $\mathrm{PS} / \mathrm{p}-\mathrm{Si}$ interface would reduce the barrier for transport of charge carrier. The illumination light is strongly absorbed by the PS films because of a limited penetration depth of the light in the pSi layer, supporting the creation of electron-hole pairs.

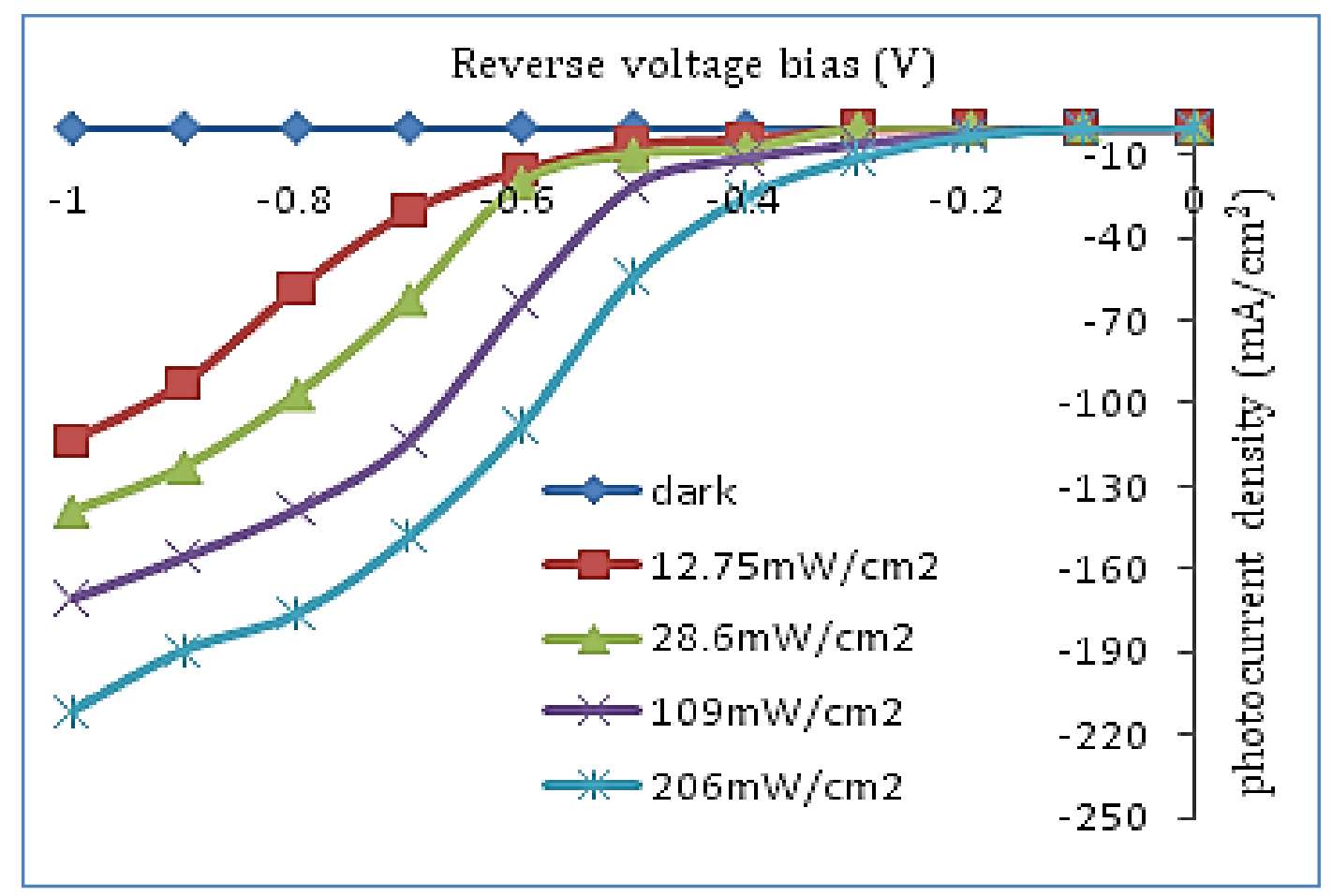

Figure 7. Photocurrent of FTO/PS/p-Si heterojunction as a function of reverse bias illuminated for different power density.

Fig. 8 shows a plot of the square of the reciprocal capacity against the applied voltage gives a straight line and this is extrapolated to $\mathrm{C}^{-2}=0$; to derive the built in voltage $\mathrm{V}_{\mathrm{bi}}$, which was of $0.95 \mathrm{~V}$.

This property gives an indication the behavior of the charge transition from the donor to the acceptor region, which is found to be "abrupt", this means that the depletion layer is constant and hence the carrier concentration will be constant at the depletion layer.

The porous layer has a much wider energy gap than the c-Si due to the quantum confinement in silicon nano crystallites. So, heterostructures PS/p-Si is considered as anisotype heterojunction since PS behaves like n-type semiconductor. 


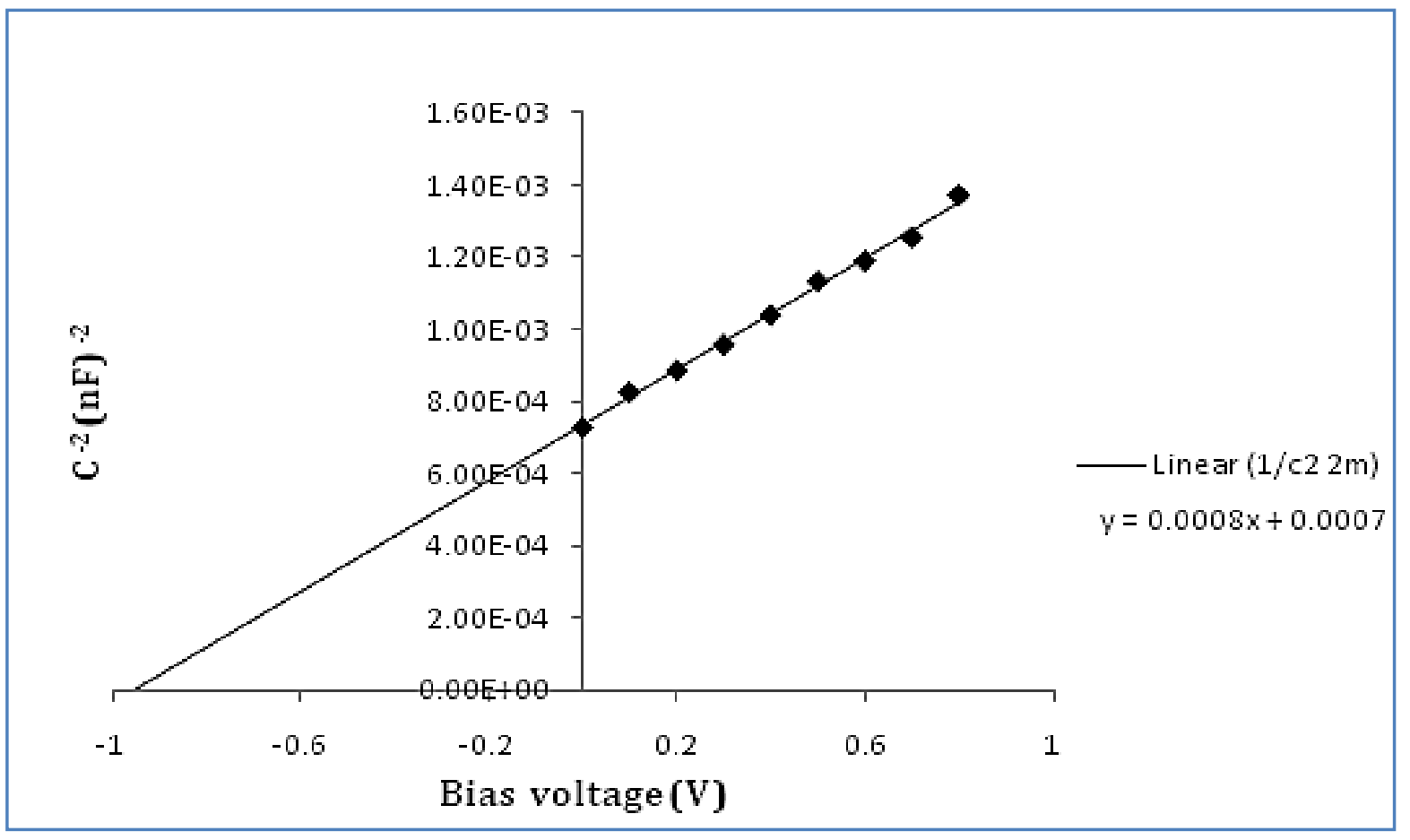

Figure 8. $\mathbf{C}^{-2}$ of $\mathrm{FTO} / \mathrm{PS} / \mathrm{p}-\mathrm{Si} / \mathrm{Al}$ vs. Bias voltage.

\section{4. Photodetector figures of merits}

Fig. 9 a and b show typical curves of the responsivity and external quantum efficiency as function of wavelength for FTO/PS/p-Si heterojunction respectively. Peak external quantum efficiency was $55 \%$ at $500 \mathrm{~nm}$ which corresponding to peak responsivity of 1.15 $\mathrm{A} / \mathrm{W}$ at 1 Vbias and these values are higher than that for the standard conventional (p-n) c-Si photodetector. Spectral distribution measurements of photoconductive signal revealed a shift of the maximum sensitivity towards visible region shorter wavelengths. It is observed that the presence of a PS layer on p-Si wafer causes a shift in this maximum peak to a higher energy and higher responsivity of the photodetector is the sum two terms the sensitivity of the FTO/PS Schottky contact and is the sensitivity of the PS/p-Si heterojunction as well as the reflectivity of porous Si for visible and near infrared regions is very low and that agree with [13]. Also, Alwan et al. reported that the porosity of the porous silicon layer leads to hence improve the sensitivity of the formed junction between the crystalline silicon and the PS layer [14].

The lower value of quantum efficiency for FTO/PS/p-Si device suggests that the interface is acting as a strong recombination site for the photo-generated carriers crossing the junction. Also may be the reflectivity of porous Si for a visible region and, incompletion absorption. At this point, Lee et al. reported that imperfect native oxide or unstable hydrogenpassivated surfaces of as-anodized PS provide large amounts of surface states in the PS layer. These states act as recombination centers and severely reduce the lifetime of photocarriers and hence lead to low quantum efficiency [15-24].

Fig. 9(c) show the energy gap for the investigated sample was $2.5 \mathrm{eV}$ and it large than $1.12 \mathrm{eV}$. As it is known the width of the band gap of crystal silicon is $1.12 \mathrm{eV}$. The enhancing of band gap in PS is connected with quantum-size effect. The main quantum confinement effect is represented by the appearance of new energy levels in the silicon band gap, so the 
increase in value of energy gap was $1.38 \mathrm{eV}$, which is an advantage if it is required as an active absorbing material in solar cells also.

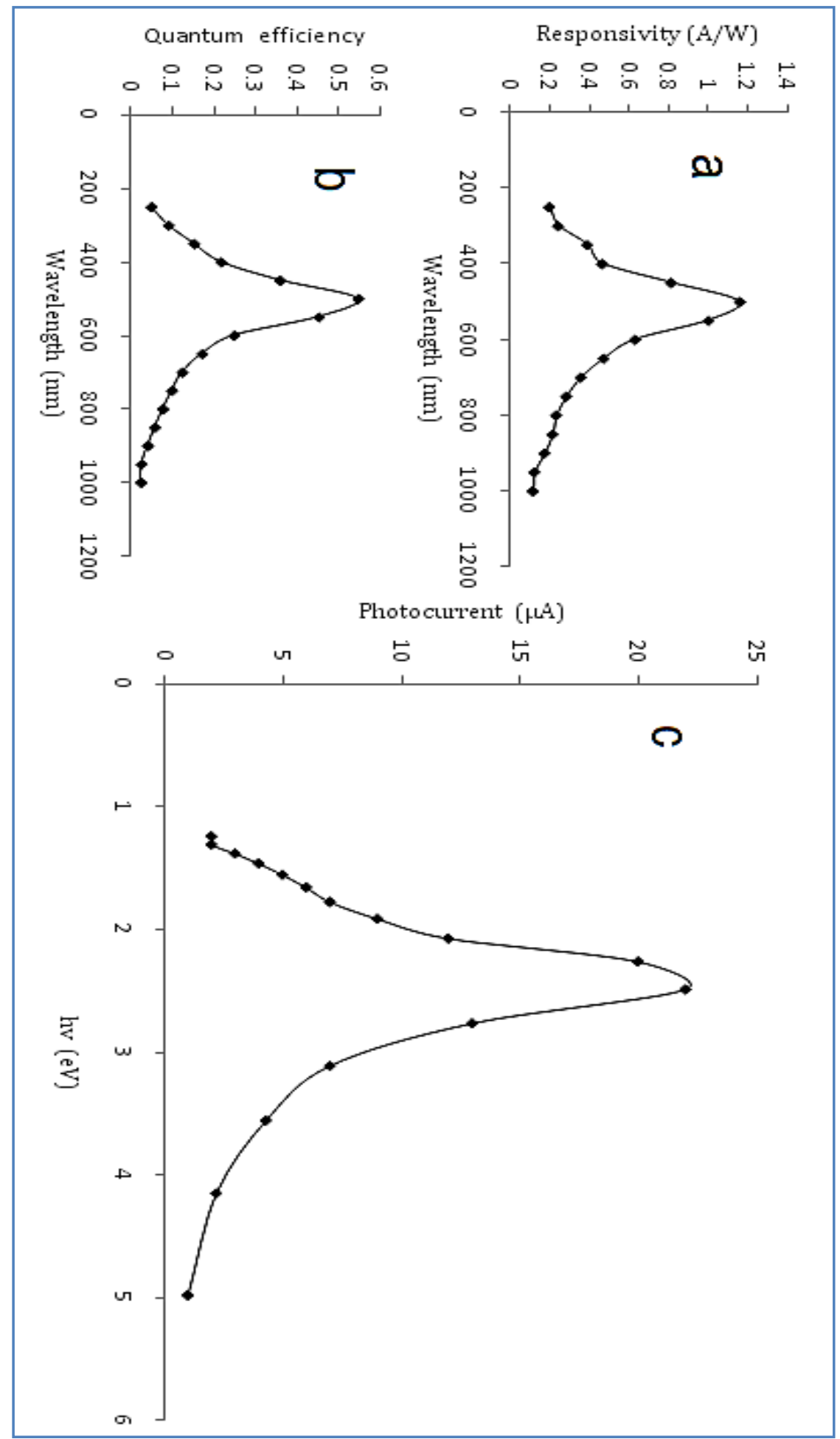

Figure 9. (a) Responsivity as a function of various incident wavelengths for structure FTO/PS/p$\mathrm{Si} / \mathrm{Al}$, (b) quantum efficiency as a function of various incident wavelengths for structure FTO/PS/p$\mathrm{Si} / \mathrm{Al}$, and (c) the spectrum of photocurrent of FTO/PS/p-Si/Al structure vs. incident photon energy. 


\section{CONCLUSION}

The morphological and optical properties of the fabricated nanostructure of FTO thin film layer was characterized by AFM, and UV-visible techniques. Also, a morphology surface property of porous silicon layer was reported. FTO/PS contact is a promising, a Schottky type contact for porous silicon-based optoelectronic devices. Our results shows that the FTO/PS/p-Si contact interface has a good responsivity and external quantum efficiency in uv-visible regions for porous silicon based photodetector device applications. It was concluded that FTO/PS/p-Si heterojunction can be produced for optoelectronic devices such as photodetector and solar cell. The PS band gap in the vicinity of PS/c-Si heterojunction can be determined by dependence of the short-circuit photocurrent of structure on photon energy hv.

\section{References}

[1] A. Cherif, S. Jomni, R. Hannachi, L. Beji, Physica B: Condensed Matter 409 (2013) $10-15$.

[2] F. A. Garces, R. Urteaga, L .N. Acquaroli, R. R. Koropecki, R. D. Arce, Nanoscale Research Letters 7 (2012) 2-6.

[3] S. Ozdemir, J. L. Gole, Sens Actuators B 147 (2010) 247-280.

[4] J. Kanungo, H. Saha, S. Basu, Sens Actuators B 147 (2010) 128-136.

[5] A. A. Yadav, E. U. Masumdar, A. V. Moholkar, K. Y. Rajpure, C. H. Bhosale, Physica B 404 (2009) 1874-1877.

[6] M. A. Aouaj, R. Diaz, A. Belayachi, F. Rueda, M. A. Lefdil, Materials Research Bulletin 44 (2009) 1458-1461.

[7] F. A. Garcés, L. N. Acquaroli, R. Urteaga, A. Dussan, R. R. Koropecki, R. D. Arce, Thin Solid Films 520 (2012) 4254-4258.

[8] V. Bilgin, I. Akyuzb, E. Ketencic, S. Koseb, F. Atayb, Applied Surface Science 256 (2010) 6586-6591.

[9] A. M. Farag, Applied Surface Science 255 (2009) 3493-3498.

[10] Z. Ahmad, M. H. Sayyad, M. Yaseen, M. Ali, World Academy of Science, Engineering and Technology 76 (2011) 811-814.

[11] H. Q. Shan, Chin. phis. Let. 24 (2007) 825-827.

[12] M. Pattabi,S. Krishnan, X. Ganesh, X. Mathew, Solar Energy 81 (2007) 111-116.

[13] R. A. Ismail, e-J. Surf. Sci. Nanotech 8 (2010) 388-391

[14] M. Alwan, A. Jabbar Modern Applied Science 5 (2011) 106-112

[15] K. Lee, Y. Tseng, C. Chu, Appl. Phys. A 67 (1998) 541-543.

[16] Nadir Fadhil Habubi, Sami Salmann Chiad, Saad Farhan Oboudi, Ziad Abdulahad Toma, International Letters of Chemistry, Physics and Astronomy 4 (2013) 1-8. 
[17] Saad F. Oboudi, Nadir F. Habubi, Ghuson H. Mohamed, Sami S. Chiad, International Letters of Chemistry, Physics and Astronomy 8(1) (2013) 78-86.

[18] J. A. Najim, J. M. Rozaiq, International Letters of Chemistry, Physics and Astronomy 10(2) (2013) 137-150.

[19] Majid H. Hassouni, Khudheir A. Mishjil, Sami S. Chiad, Nadir F. Habubi, International Letters of Chemistry, Physics and Astronomy 11 (2013) 26-37.

[20] K. K. Patankar, International Letters of Chemistry, Physics and Astronomy 1 (2014) $1-8$.

[21] Hanan R. A. Ali, International Letters of Chemistry, Physics and Astronomy 8 (2014) 47-55.

[22] Raghad Y. Mohammed, S. Abduol, Ali M. Mousa, International Letters of Chemistry, Physics and Astronomy 10 (2014) 91-104.

[23] Raghad Y. Mohammed, S. Abduol, Ali M. Mousa, International Letters of Chemistry, Physics and Astronomy 11(2) (2014) 146-158.

[24] Ali M. Mousa, Slma M. Hassen, S. Mohmoed, International Letters of Chemistry, Physics and Astronomy 15 (2014) 1-10. 